\title{
Pedicle Flap Coverage for Infected Ventricular Assist Device Augmented with Dissolving Antibiotic Beads: Creation of an Antibacterial Pocket
}

sasha still ${ }^{1}$, Rene Myers ${ }^{1}$, Jose Tallaj², Salpy Pamboukian², William Holman ${ }^{1}$, James Davies $^{1}$, Charles Hoopes ${ }^{1}$, and Erik Orozco-Hernandez ${ }^{1}$

${ }^{1}$ The University of Alabama at Birmingham Department of Surgery

${ }^{2}$ The University of Alabama at Birmingham Department of Medicine

April 27, 2020

\begin{abstract}
Infectious complications following left ventricular assist device implantation can carry significant morbidity and mortality. The main tenet of treatment is source control which entails local wound care, intravenous antimicrobial therapy, surgical debridement, and at times, soft tissue flap coverage. The mode of therapy depends on the severity, etiology, and location of infection as well as the clinical status of the patient. We describe a case of a 46 year old male who underwent left ventricular assist device placement complicated by pump thrombosis, recurrent infection, and hardware exposure who was successfully treated with a novel method of staged, soft tissue reconstruction.
\end{abstract}

Hosted file easterwoodv ${ }_{f}$ inal $_{1}$ 500.pdfavailableathttps : //authorea.com/users/315110/articles/445485 pedicle-flap-coverage-for-infected-ventricular-assist-device-augmented-with-dissolvingantibiotic - beads - creation - of - an - antibacterial - pocket 


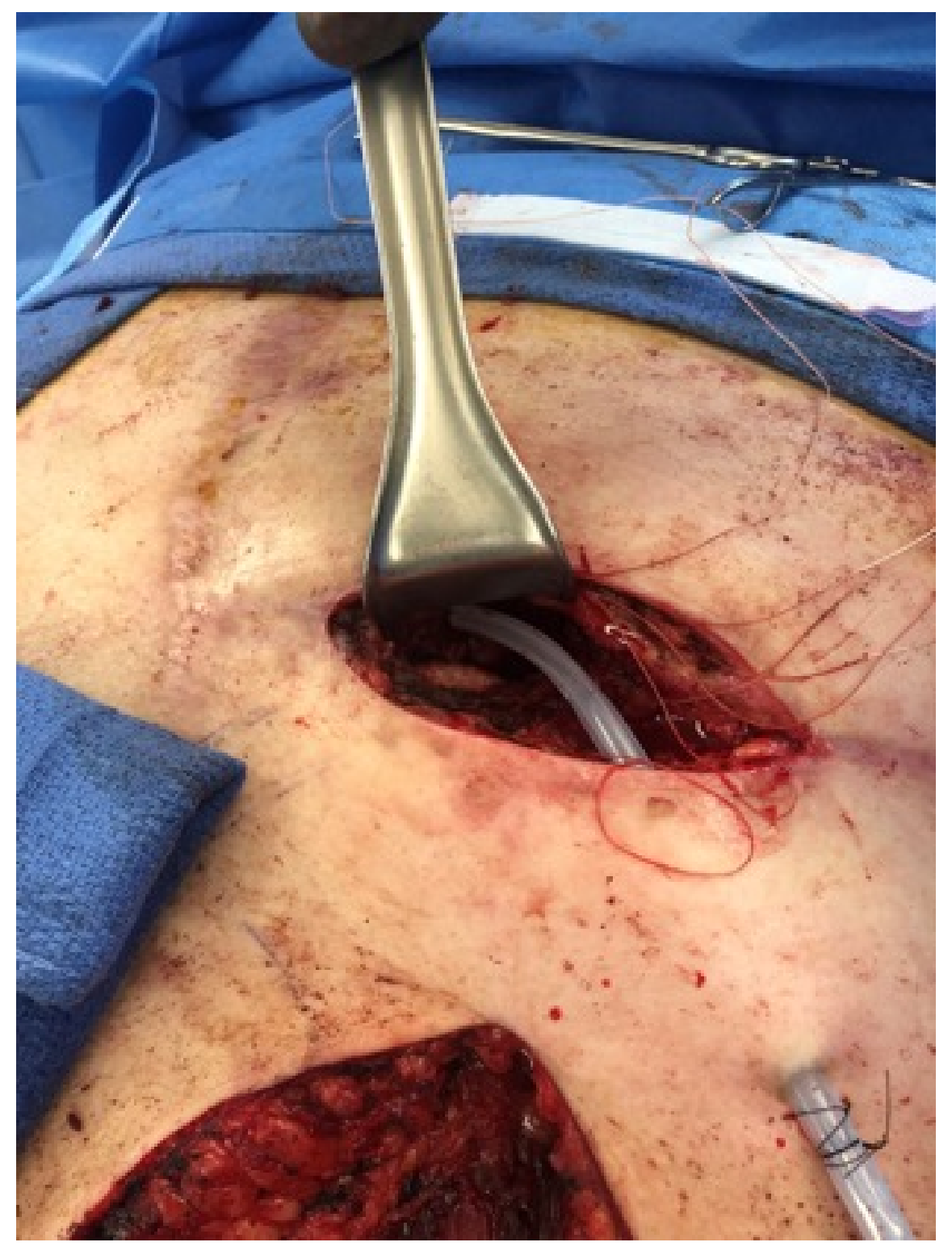




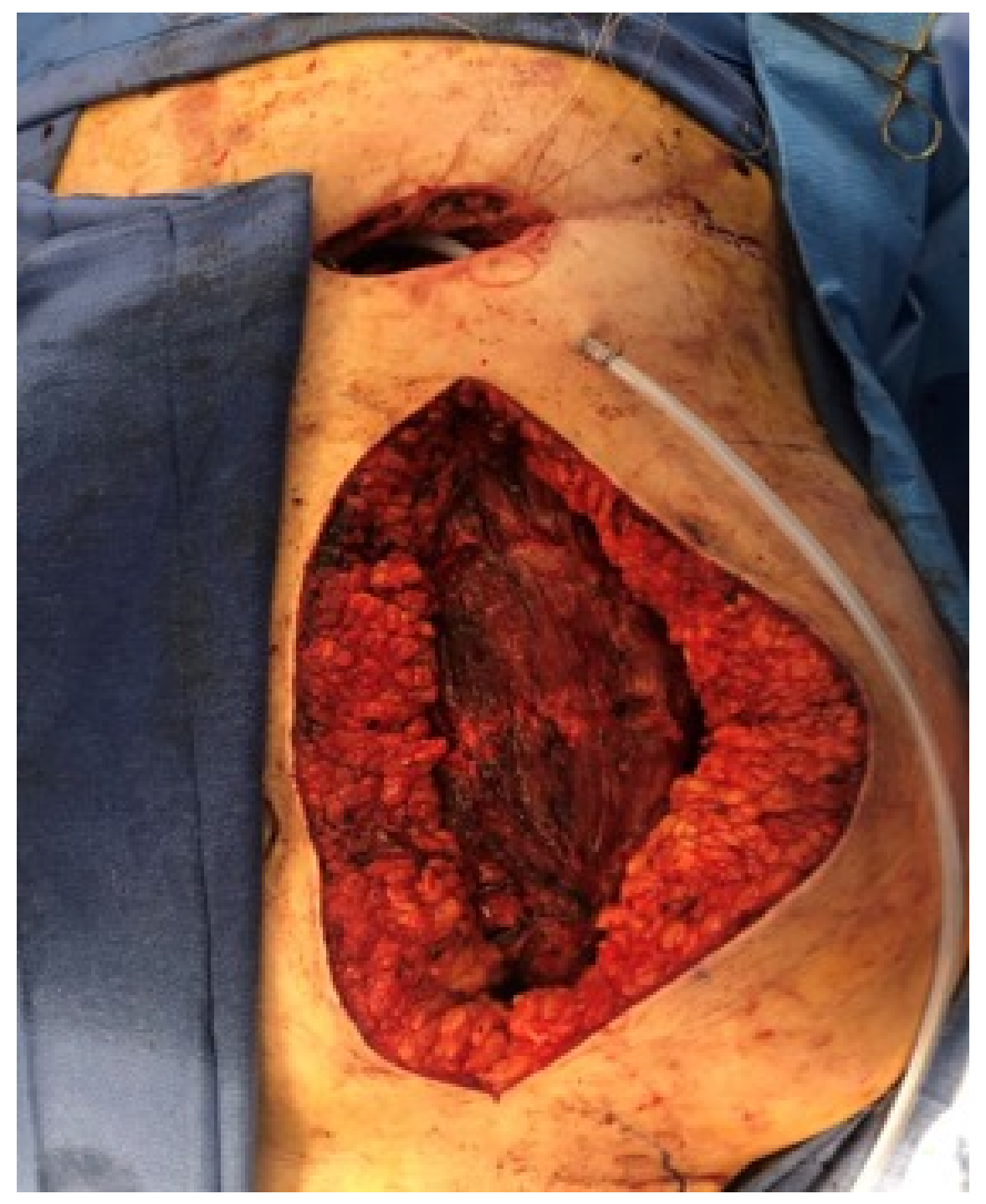




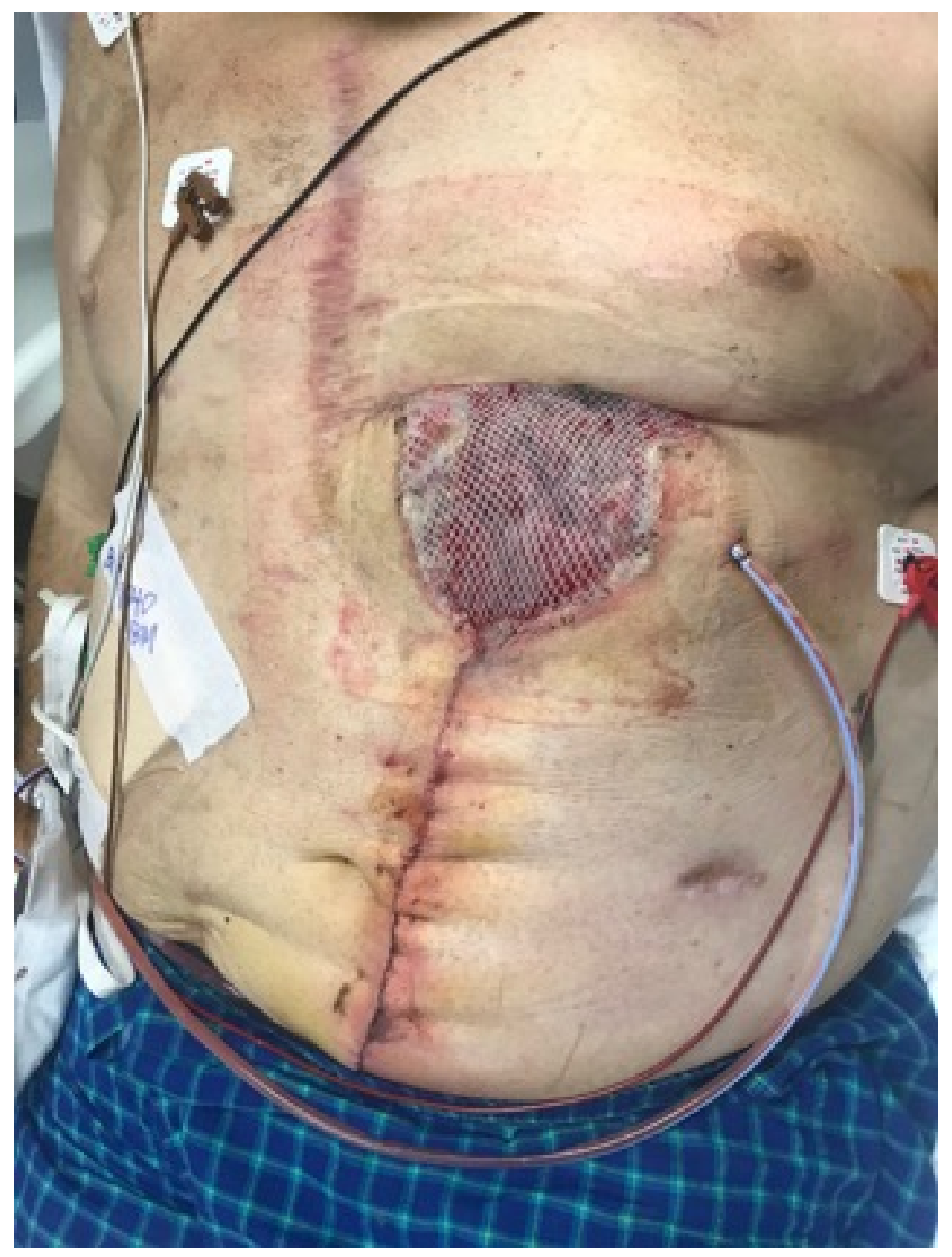

